\title{
Risk factor and Outcomes of Diabetic Foot Ulcer among Diabetes Mellitus Patients Admitted to Nekemte Referral Hospital, Western Ethiopia:Prospective cohort study
}

Firomsa Bekele ( $\nabla$ firomsabekele21@gmail.com )

Mettu university

Legese Chelkeba

Jimma university

Ginenus Fekadu

Wollega University

Kumera Bekele

Selale university

Research article

Keywords: Diabetic Foot Ulcer, Risk Factors, Outcomes,Nekemte Referral hospital

Posted Date: January 21st, 2020

DOI: https://doi.org/10.21203/rs.2.12896/v2

License: (c) (i) This work is licensed under a Creative Commons Attribution 4.0 International License.

Read Full License 
The authors have withdrawn this preprint from Research Square 